\title{
Permanent or temporary settlement? A study on the short-term effects of residence status on refugees' labour market participation
}

\author{
Kristoffer Jutvik ${ }^{1} 2^{*}$ (iD and Darrel Robinson ${ }^{2}$
}

\author{
${ }^{*}$ Correspondence: \\ kristoffer.jutvik@ibf.uu.se \\ ${ }^{1}$ Institute for Housing and Urban \\ Research, Uppsala University, \\ Trädgårdsgatan 18, 75120 Uppsala, \\ Sweden \\ 2Department of Government \\ Uppsala University, Gamla torget 6, \\ 75320 Uppsala, Sweden
}

\begin{abstract}
Whether refugees in need of protection should be granted long- or short-term residence permits in the host country upon arrival is a long-standing debate in the migration policy and scholarly literature. Rights-based models of inclusion advocate for secure and long-term residency status arguing that this will provide the foundations for successful inclusion. Responsibilities-based models on the other hand claim that migrants should only be granted such status if certain criteria, such as full-time employment, have been met, again under the belief that such a system will facilitate inclusion into the host society. Using a sudden policy change as a natural experiment combined with detailed Swedish registry data, we examine the effect permanent residency on three measures of labour market inclusion in the short-term. Our findings are twofold. On the one hand, we find that temporary residents that are subject to a relatively less-inclusive situation have higher incomes and less unemployment. However, at the same time, they are less likely to spend time in education than are those with permanent residency.
\end{abstract}

First part title: Permanent or Temporary Settlement?

Second part title: A Study on the Short-Term Effects of Temporary and Permanent Residence Permits on Labour Market Participation

Keywords: Labour market inclusion, Asylum policy, Refugees, Residence permit

\section{Introduction}

Humanitarian crises throughout the Middle East, South Asia, and Africa have greatly increased immigrant inflows to Europe in recent years, which has subsequently impacted upon the politics of European recipient nations. Anti-immigration parties have grown largely on the basis of ethnocentric and nationalistic rhetoric - and a large debate has arisen around how best to include those individuals that are eligible for asylum in host countries into the labour market and wider society.

In recent decades, there has been a shift in migration politics across European countries. This shift has frequently been labelled as a convergence towards increasingly assimilatory

(c) The Author(s). 2020 Open Access This article is licensed under a Creative Commons Attribution 4.0 International License, which permits use, sharing, adaptation, distribution and reproduction in any medium or format, as long as you give appropriate credit to the original author(s) and the source, provide a link to the Creative Commons licence, and indicate if changes were made. The images or other third party material in this article are included in the article's Creative Commons licence, unless indicated otherwise in a credit line to the material. If material is not included in the article's Creative Commons licence and your intended use is not permitted by statutory regulation or exceeds the permitted use, you will need to obtain permission directly from the copyright holder. To view a copy of this licence, visit http://creativecommons.org/licenses/by/4.0/. 
politics (Joppke 2004; Joppke 2017) and a retrenchment of multiculturalism (Vertovec and Wessendorf 2010). From a theoretical standpoint it has been noted that the shift has decreased emphasis on individual rights for a greater insistence on individual responsibilities (Borevi 2010). In short, responsibilities-based models argue that individuals need to make an effort to belong, whereas rights-based models perceive individual rights as the driver of inclusion. Of particular focus has been the construction of citizenship, of which residency status constitutes a central component. Theoretically, responsibilities-based models argue that migrants should be given limited residence subject to re-evaluation for which only those that succeed in integrating into the labour market should be given the right to stay. Rights-based models on the other hand argue that migrants should be given permanent residency, and that this right to stay should not be conditional on labour market inclusion. This inclusion is in turn intended to improve migrants' possibilities to integrate into the labour market and wider society. However, the implications of residency status on labour market inclusion are largely unknown. The research question this paper addresses is thus: What is the effect of permanent residency status on labour market inclusion?

Looking at the current state of literature, there are a number of works that study mandatory integration, which base secure residency or citizenship on language skills, norm adherence, and cultural-historical knowledge shown by the migrant (Strik et al. 2010; Goodman and Wright 2015; Goodman 2010; Goodman 2011; Borevi et al. 2017). ${ }^{1}$ Other lines of research focus on the impact of residency status on non-labour outcomes such as health or psychological well-being (e.g. (Ryan et al. 2008; Bogic et al. 2015; Bakker et al. 2014)), or have compared labour market outcomes across different nation-states (e.g. (Koopmans 2010; Kogan 2007; Kogan 2006; Mansouri et al. 2010; Kesler 2006; Bevelander and Pendakur 2014)). Although providing valuable insights, comparisons between nation-states are problematic as the included cases may differ along other dimensions, for instance, internal migrant populations, institutional setups, preexisting immigrant networks, or reception policies, all of which may obstruct causal inference. Two recent contributions study the effect of residency permit on labour market participation (and other outcomes) explicitly but have led to mixed conclusions. On the one hand, Larsen et al. (2018) have suggested that restrictive policy measures in Denmark (prolonging the access to permanent residency) had a positive effect on enrolment in education, but no significant effect on labour market participation. On the other hand, Blomqvist et al. (2018) have shown that individuals with permanent residency are more likely to take part in language training compared to those with temporary residency. Similar to the Danish study, the authors do not find any significant effect of residency status on labour market participation. Furthermore, these studies include groups that largely consist of refugee-status migrants which limits the scope of the treatment - residency permit - as the factors that define refugee-status are largely time-invariant. ${ }^{2}$

\footnotetext{
${ }^{1}$ Mandatory integration policies demand acquisition of citizen-like skills, such as host country language, norms, culture, or history, in order to become a full member. See Goodman and Wright (2015) for a detailed description. See also Borevi et al. (2017) for a review of the literature.

${ }^{2}$ The group of refugees in our sample consist of a vast majority of individuals granted subsidiary protection status due to the Syrian conflict itself (see Table 1). As such, from the perspective of the individuals in our sample, at the time they were granted residence, they had no idea how long the conflict would last or what the status of the conflict would be upon the re-evaluation of their permit. Thus, as indicated in previous studies (Beskow 2018, p. 6), refugees with temporary residence permits based on subsidiary protection status face a particularly vulnerable position in regards to their security of residence in comparison to other groups of refugees granted refugee-status, i.e. protection based on non-time variant factors such as gender, sexual orientation, or ethnicity.
} 
With this in mind, this paper takes a somewhat different approach by exploiting a swift change of policy implemented in Sweden concerning asylum-seekers from Syria. Before implementation of the policy change, most Syrian asylum-seekers that came to Sweden were given temporary residency. In 2013 the Swedish Migration Agency (SMA henceforth) abruptly re-assessed their evaluation of the Syrian conflict, which had as a consequence that all asylum-seekers from Syria were to be given permanent residency. ${ }^{3}$ As the policy change was implemented without prior warning, it provides a threshold between Syrian refugees that applied for residency under two different regulations. We exploit this threshold as a quasi-experiment to study the effect of permanent residency on labour market inclusion in the short-term.

From an international perspective, Sweden is often associated with a rights-based policy approach and a high intake of refugees (Koopmans 2010). In Esping-Andersen's seminal typology (Esping-Andersen 1990), Sweden is categorized as a social-democratic welfare state marked by the provision of a large set of social services and an aim to reduce social inequalities. Although several studies have pointed to a positive effect of human capital in the Swedish setting (Aldén and Hammarstedt 2014; Hammarstedt 2003; Dahlstedt and Bevelander 2010), other studies have shown that the pay off from education is lower in comparison to other countries, such as the US (Nekby 2002), which is categorized as a liberal welfare state. In comparison to other countries, it takes longer time for migrants to receive the same financial return from education compared to natives. Several studies have suggested that the Swedish labour market, although providing a large set of services, provide limited opportunities for migrants on the labour market despite their education, potentially due to discrimination (Kelly and Hedman 2016; Hammarstedt 2003). ${ }^{4}$ In this study, it is important to have in mind that both cohorts had access to the same welfare services but also experienced the same challenges and constraints present in the Swedish setting with the exemption of residence status.

This study brings a few additions to the existing literature. First and foremost, it explicitly focuses on the effects of residency status on labour market inclusion. Until this point, there is little knowledge of the specific impact of temporary and permanent settlement on these outcomes in existing studies. This is of interest because labour market outcomes are the most commonly debated in policy and theory, and for which both models, the rights-based and responsibilities-based, are claimed to be superior. Second, we make use of detailed individual data containing the full population under scrutiny. Opposite to comparative approaches, this study investigates the effect of temporary and permanent residence permits within one nation thus holding confounding variables such as institutional, cultural, and historical variation constant. Lastly, while this study only focuses on the short-term inclusion into the labour market, we do so with estimates of outcomes after two different lengths of time in Sweden. The importance of early settlement have been emphasized in previous studies and this approach allows us to identify at which point observed outcomes as the result of residency permit manifest (OECD 2016a; OECD 2016b).

The conclusions of this study are twofold. We find that temporary residents have higher incomes and are unemployed less. However, at the same time, they are less likely to

\footnotetext{
${ }^{3}$ Note that the recognition rate for Syrian asylum-seekers was $100 \%$ before and after the policy change.

${ }^{4}$ Keller and Hedman (2016) have suggested that the limited opportunities on the Swedish labour market encouraged Iranians with high education to leave Sweden for countries with, in their view, more favourable labour markets.
} 
spend time in education than are those with permanent residency. Given these findings, it is clear that less-secure residence status is beneficial to labour market inclusion in the short-term. However, the greater focus on education among those with permanent residency raises the possibility that long-term inclusion may not follow the same patterns. It should, however, be noted that there are a few aspects of the policy change that challenges a clear identification of its effects. We, therefore, apply three different research designs in the paper all of which point to the same conclusions. Our results suggest that both approaches to migration policy can be supported empirically, albeit with different metrics for success. In our view then, the issue should be viewed as largely normative. Rather than debate whether one approach will lead to greater inclusion than the other, focus should be shifted to discussing the type of inclusion that the different approaches are likely to provide.

\section{A theoretical framework on security of residence}

We propose a theoretical model, inspired by Borevi (2002) and Koopmans (2005), in which residency status is defined as a uni-dimensional scale that outlines different levels of security. The position at the left-side of the continuum, insecure residency, refers to a position in which individuals are largely excluded from full membership, and residency status relies exclusively on attachment to a specific job or program of study. If the required attachment is lost, then the basis for residency is immediately withdrawn. Hence, this position refers to an unpredictable and insecure status in which the individual has to perform in a pre-stipulated manner in order to maintain residency. At the right end of the continuum, secure residency refers to a position in which full membership is granted into a community of citizens. In this position, residency cannot be withdrawn and hence refers to an increasingly predictable and secure type of residency.

In our theoretical model, we argue that temporary and permanent residency are found in between the above extremes. This is visualized in Fig. 1. Temporary residency is found closer to the left, insecure, end of the scale because an individual's status will be reassessed after a pre-determined period of time. In the event that the grounds for residency change, and one lacks attachment to the host society such as through employment, residence status is not typically renewed upon re-assessment. However, temporary residents do not rely on a specific attachment during their limited time of residence. On the other hand, permanent residence is found on the right-side of the scale. Individuals granted permanent residency are not yet fully included in the membership of citizens but they benefit from secure residency that is not subject to re-assessment after a given time period, and thereby is not conditional on employment or study.

\section{Residency status and the labour market}

Human capital theory stipulates that an individual's earnings are determined as a function of work experience and skills such as those developed in education (Mincer 1974;

\begin{tabular}{|c|c|c|c|c|}
\hline \multirow{3}{*}{$\begin{array}{l}\text { Residency } \\
\text { status }\end{array}$} & Conditional residence & Temporary residence & Permanent residence & Citizenship \\
\hline & & & & \\
\hline & Insecure residence & & & cure residence \\
\hline
\end{tabular}

Fig. 1 A Theoretical model on security of residence. Figure displays the continuum in residency status ranging from insecure residency to secure residency 
Chiswick 1978; Dahlstedt and Bevelander 2010). If individuals can bear the cost of education in the short-term, as well as the indirect costs related to loss of income and work experience, long-term benefits will lead one to prefer education. This model has been highly influential in understanding why individuals with higher education have higher earnings on average. The human capital framework can be applied to explain migrant earnings as well with respect to education in a recipient country. Migrants that study in their new country, whether it be language training (Chiswick 1991; Lemaître and Liebig 2007; Ferrer et al. 2006), higher education (Nekby 2002; Hammarstedt 2003; Aldén and Hammarstedt 2014), or a specific certificate relevant to the given labour market (Dahlstedt and Bevelander 2010), are consistently found to have higher incomes in the long-term than those migrants that do not study upon arrival to their new country. When migrants study in the host country, they develop skills that are adapted to the local labour market, and receive credentials that are immediately recognized, which facilitates the transition into the new labour market.

For those granted permanent residency, the short-term long-term trade-off as outlined in the human capital function remains unchanged. However, an insecure residency status has the possibility to influence this model as long-term benefits must be discounted given that one cannot be sure to realize them. The literature on civic integration suggests that residence status should depend on performance such as labour market attachment. Migrants that fail to accommodate the desired requirements are refused renewal of residency (Bee and Pachi 2014; Borevi 2010; Koopmans 2010). This incentive, or restriction, means that individuals that aim to remain in their recipient country must discount long-term earnings that may come from education in favour of short-term labour market attachment that will ensure residency renewal. In line with this argumentation, we propose the following hypotheses:

- Permanent residency should lead individuals to work less than temporary residents in the short-term.

- Permanent residency should lead individuals to study more than temporary residents in the short-term.

\section{The institutional setting}

After the outbreak of the conflict in Syria the Swedish Migration Agency (SMA) crafted a number of internal documents containing guidelines and descriptions of the development of the conflict. These documents, referred to as RCI (Instructions from the General Counsel), ${ }^{5}$ served to guide case workers in the assessment of the mounting number of applications from Syria. Without going into the specifics of these documents, ${ }^{6}$ the general guideline prior to the 2013 change was that Syrian asylum-seekers were to be granted temporary residence in Sweden, allowing three years of settlement (RCI 14/2012 2012). However, permanent residency could be granted if individuals were considered to be convention refugees. ${ }^{7}$ In 2012 the share of temporary residence permits was $61 \%$ of all granted Syrian applications. This figure had risen somewhat in 2013 in which the share of temporary residence permits was roughly $73 \%$ of all granted Syrian applications.

\footnotetext{
5 "Rättschefens instruktioner" in Swedish

${ }^{6}$ For a more detailed description of the guidelines provided by the SMA, see (Andersson and Jutvik 2019).

${ }^{7}$ In accordance with the Geneva Convention, a person is a refugee if he or she has a well-founded fear of persecution due to race, nationality, religious or political beliefs, gender, sexual orientation or affiliation to a particular social group.
} 
On September 3, 2013 the SMA made a new evaluation of the conflict in Syria (RCI 14/2013 2013), which resulted in the policy change of focus in this study. The General Counsel stated that the conflict was in a dead lock position and that both sides believed victory possible and near. The SMA also noted that the number of actors participating in the conflict had increased. As a consequence of the increased complexity of the conflict, the General Counsel made the judgement that the unrest in Syria would go on for an extensive period of time and stated that all Syrian asylum-seekers should be granted permanent residence. Hence, after the policy change, $100 \%$ of applications were granted permanent residence permits even if not considered convention refugees.

There are a few important details about the policy change that have significant implications for the choice and implementation of our research design. First, the change was implemented immediately, providing a cut-off between those awarded temporary and permanent residence permits. As shown in Fig. 2, there is a clear jump at the implementation of the new directives, where the share of permanent residence permits sharply rises from about $35 \%$ to $100 \%$. Second, the change of directives were implemented by the SMA without prior announcement. Hence, it was not a political decision or the result of a long parliamentary debate - no awareness was made of an impending change in the period prior to the reform. This setup made it impossible to react to the change before the actual implementation. The sudden implementation, in combination with detailed data from the SMA, allows us to identity a treatment group unaffected by any potential sorting - those individuals that applied before, but were granted residency after, the change in policy. Lastly, the policy change implied that all individuals that had been granted temporary residence permits prior the change could apply for a re-evaluation of their permits in order to make them permanent. The majority of Syrians with temporary permits also applied for the re-evaluation immediately. These applications for extensions were largely processed by the SMA before the end of the year. ${ }^{8}$

\section{The introduction program}

The introduction program is available to all newly arrived refugees during their first two years of residence in Sweden. The program contains language training (SFI) and civic orientation, but also the development of an individual plan with the aim to facilitate entry to the labour market (Larsson 2015). Although the program is not mandatory, only those that participate receive the attached financial benefits. Hence, there is a strong incentive to participate. The financial support provided in the program is slightly higher than the general social assistance available to all Swedes and is not affected by the income of other household members. Participants are also allowed to work during the program (OECD 2016a).

Given the structure of the program, in which benefits are dependent on participation, we assume that the individuals under scrutiny here were part of the program during the time of investigation. The program gives several alternatives for participants in terms of language training, preparation for work, and educational activities in combination with activity on the labour market (OECD 2016a).

${ }^{8}$ Data from the SMA indicate that $99 \%$ of all applications for re-evaluation were handed in to the SMA before the end of 2013. The SMA had processed 77\% of these applications in the end of 2013 and 91\% in the end of January 2014. 


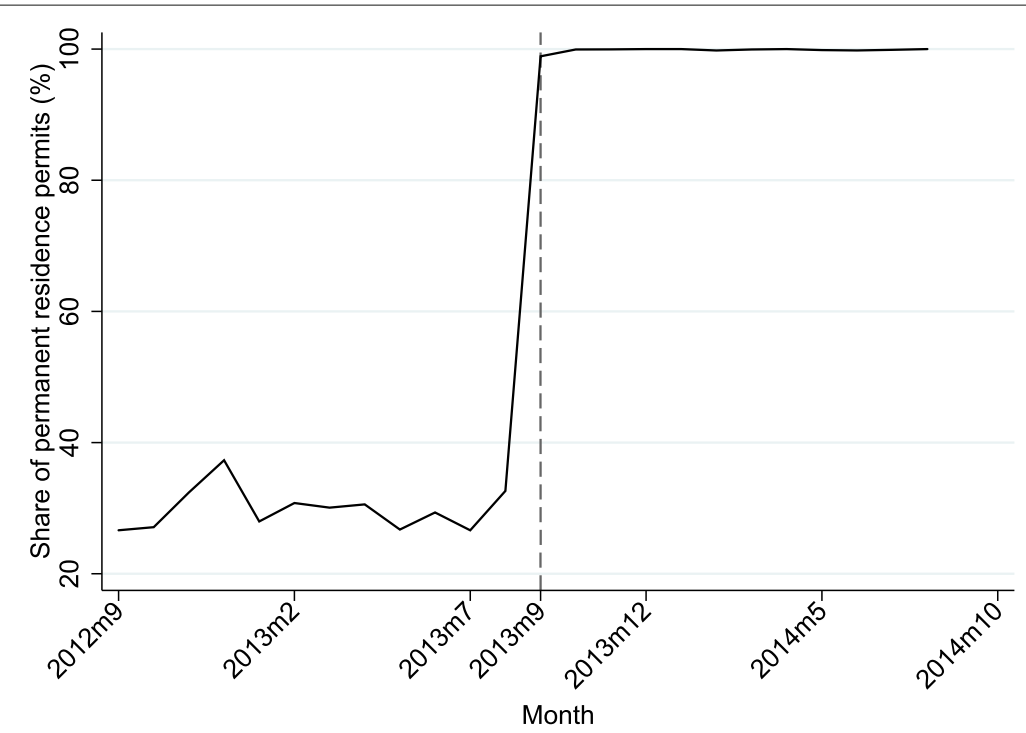

Fig. 2 The share of permanent residence permits among all granted residence permits (among Syrian applications). Share of permanent residence permits among all granted residence permits. Data concerns distribution among Syrian applications only. Note that the recognition rate was $100 \%$ before and after the policy change

\section{Methodological setup, data and samples}

This study relies on a detailed database of individual-level Swedish register data. The database, GEOSWEDEN, contains anonymous information on all residents with a registered address in Sweden between 1990 and 2014. With this data-set we obtain information regarding, among many other things, individual demographics, labour market status, education, country of birth, month of granted residence permit, and reason for approved migration application (grund för bosättning).

In our methodological setup, we make use of the sharp introduction of SMA's policy change, which provides a cut-off determining residency status. Because the decision from the SMA was so sudden and without prior indications of an impending change, those that were approved for asylum after, but who applied before, September 3, 2013 were entirely unaware that they would be guaranteed to receive permanent residency upon approval. As such, their applications would have been made with the knowledge that the majority of successful asylum applicants received temporary status. This group of individuals, those that applied before but for whom a decision was taken after the change in policy, make up our treatment group.

We do not observe the date of application and date of decision at the individual-level in GEOSWEDEN. Rather, our data allows us to see only the month a residency decision was granted. This creates two potential problems in defining the start and end of our treatment group, however, we circumvent these in two ways. First, in defining the start of our treatment group we rely on the fact that the change was made at the beginning of the month, on September 3, 2013. That means that effectively all individuals for whom a decision was made in the month of September were subject to the new rules. ${ }^{9}$ Inferring

${ }^{9}$ September 3 was a Tuesday which means that only individuals whose decisions were made on Monday, September 2 would have been subject to the old rule, all others who were decided in September were subject to the new rule. There were 927 decisions made in the entire month of September, which equates to 44 per working day on average. However, the length of time for a decision decreased drastically after the rule change, which would indicate that more decisions 
application outcomes based on monthly-level data is therefore not problematic and allows us to overcome the issue of treatment "start" in the absence of daily data.

The second issue is that we cannot define the "end" of our treatment period at the individual-level. That is, we know that all individuals that were awarded residency after September 3, 2013 were given permanent residence, but if we include individuals into our treatment group that applied for residency after September 3 our sample will have self-selected into treatment. In order to solve this problem, we make use of data from the SMA containing anonymous individual-level application and decision dates (though we are unable to connect this to individuals in the GEOSWEDEN database through lack of identifying information). The data from the SMA shows us that $96.38 \%$ of all Syrian asylum decisions made in September 2013 were based on applications that had been submitted prior to the September 3 threshold. This proportion decreases quite rapidly in the following months; only $57.6 \%$ of applications granted in October were based on prereform submissions, and this drops further to $23.13 \%$ in November. As such, we can with confidence define our treatment window as all of those individuals for whom an asylum decision was granted in September 2013. After removing those below the age of 18 and over 65 from our sample, we obtain a treatment group comprised of 629 individuals.

We define our control group as all individuals from Syria that were granted residency in September of 2012, exactly one year prior to our treatment group. Such a definition allows us to hold constant the amount of time individuals had been in Sweden across treatment and control groups when we measure our dependent variables (dependent variables are measured at the end of an individual's first full year in Sweden or after 4 to 11 months in the synthetic control group approach). Further, migration is highly seasonal so the selection of refugees based on granted asylum month should further ensure comparability. The most natural control group would have been to select those individuals that were granted residency in the period immediately prior to the change in policy directive, for example those that were granted residency in August 2013. However, the provision which allowed all of those individuals who had been previously been granted temporary residence to apply for a re-evaluation, prevents the use of such a strategy.

Comparing labour market indicators across years can naturally lead to problems if economic conditions differ year-to-year. However, for our two years of interest we see very little change in economic indicators. GDP growth was 1.2\% in 2013 and 2.6\% (World Bank 2020) in 2014 and foreign-born unemployment was exactly equal at $16.4 \%$ in both years (OECD 2020). In general, the labour market conditions for our two groups were largely equal, if not slightly beneficial to the 2013 cohort of permanent residents. However, it is nevertheless possible that the labour market for new arrivals specifically differs year-to-year. We therefore leverage the labour-market outcomes of all other non-Syrian asylum-seekers as a comparison group. These approaches will be further described below.

Another potential problem is that the intensity of the Syrian conflict itself might affect the strategies concerning labour market participation as well as ideas about a return to Syria among the cohorts. Here, it is important to note that the SMA considered the conflict in Syria to be in a state of general violence before and after the policy change. By the judgment of the SMA, this meant that all individuals risked their life only by being on Syrian territory during this period and the incentives to return to Syria should, therefore,

were made per day after the rule change than before, and that the number of decisions made in September 2013 but before the reform is likely lower than this daily average. 
be low among both cohorts. Moreover, qualitative evidence suggest that most Syrian refugees abandoned the idea of returning to Syria after deciding to go to Europe (Jörum 2015).

\section{Data and sample}

The data for our primary analyses are taken from all asylum-seekers in the years 2012$2014,{ }^{10}$ which is the height of Syrian migration to Sweden. In Table 1 we present some descriptive statistics of Syrian asylum-seekers for whom residency was granted in September 2012 and September 2013. As seen in the table, gender and the age structure is relatively stable. However, moving on to the share of married individuals and individuals with children reveals an increase by 7 and 13 percentage points respectively. In addition to that, there is also a substantial increase in individuals with university education. ${ }^{11}$

The focus of this paper is labour market inclusion, which motivates the selection of our dependent variables. We use three measures, number of days registered as unemployed, amount of study support received (in 100s of Swedish Kronor), and declared income (in 100s of Swedish Kronor). These are all measured as totals for the calendar year in the year after an individuals arrival to Sweden. In other words, for the control group that arrived in 2012, all dependent variables are measured in 2013, and for the treatment group that arrived in 2013, all dependent variables are measured in 2014.

A primary assumption that our research design relies upon is the comparability of our control and treatment cohorts. As can be seen in the Table 1, 2012 arrivals are largely similar to the 2013 arrivals in terms of gender, age and the proportion that are considered convention refugees. As mentioned, there are some differences. If those that make up the 2012 cohort have baseline characteristics that make them more likely to succeed on the labour market than the 2013 cohort, our results could be biased. Level of education is precisely such a potential factor. However, we find here that the proportion of university educated is higher among our 2013 cohort than the 2012; in other words, our treatment group is more highly educated than the control group. As such, based on the descriptive differences we observe between cohorts, this sample provides a hard test of our hypotheses that permanent residents should work less and study more in the short-term than temporary residents.

\section{Results}

Baseline results - did the change in residency status affect inclusion?

In Table 2 we present the estimated effects of residency status in a direct comparison of permanent and temporary residents that arrived in September 2013 versus September 2012 respectively. All outcomes are measured in December of the year after arrival. For each of the three dependent variables we estimate the effect of residency status with and without demographic controls. Perm Res is the coefficient of interest which represents the estimated difference between those with permanent (coded as 1 ) and temporary residency (coded as 0). Because this variable is dichotomous, we can interpret it as a difference in means of the dependent variable for the two residency status groups (conditional on the demographic covariates in the models for which they are included).

\footnotetext{
${ }^{10} 2014$ is the latest wave of data available to us.

${ }^{11}$ The data regarding education is somewhat problematic since validation of foreign education might differ over cases. We control for these differences in our estimations but acknowledge that the differences between the groups might be smaller.
} 
Table 1 Individual characteristic-differences between asylum-seekers arriving 2012 and 2013

\begin{tabular}{llll}
\hline Year & 2012 & 2013 & Difference \\
\hline Population (September): & $\mathrm{N}=274$ & $\mathrm{~N}=629$ & $-0,03$ \\
Men & 0,65 & 0,62 & $-1,29$ \\
Age & 36,18 & 34,89 & $-0,02$ \\
Young & 0,49 & 0,51 & 0,00 \\
Middle age & 0,40 & 0,40 & $0,07^{* *}$ \\
Married & 0,49 & 0,56 & $0,13^{* * *}$ \\
With children & 0,36 & 0,49 & $0,16^{* * *}$ \\
With university education & 0,20 & 0,36 & \\
Protection status (\%): & & & 0,03 \\
$\quad$ Subsidiary protection & 0,82 & 0,85 & $-0,03$ \\
$\quad$ Convention refugees & 0,18 & 0,15 & \\
Place of residence (\%): & & & $-0,09^{* * *}$ \\
$\quad$ Metropolitan cities & 0,23 & 0,14 & $-0,06^{* * *}$ \\
$\quad$ Stockholm & 0,12 & 0,06 & $-0,07^{* * *}$ \\
$\quad$ Non-SMA facilitated accommodation* & 0,41 & 0,34 & \\
Outcome variables: & & & $7,88^{* * *}$ \\
$\quad$ Unemployment days & 37,10 & 44,99 & $-65,30^{* * *}$ \\
$\quad$ Declared income & 73,68 & 8,37 & $2,180^{* * *}$ \\
$\quad$ Study grants & 0,50 & 2,69 & $5 e p+m b *$
\end{tabular}

Table display differences in characteristics among those arriving in September 2012 compared to those arriving in September 2013. The variables are measured in the end of the year that the residence permit was granted. ${ }^{* * *} p<0.01,{ }^{* *} p<0.05$. ${ }^{*}$ There are two housing options in Sweden: accommodation facilitated by the SMA (so-called ABO) and accommodation that the individual arranges by his or hers own networks (so-called EBO). Living in non-SMA facilitated accommodation have been suggested to have a positive impact on labour market participation (Bevelander et al. 2009). We do not have access to data which allows us to control for type of residence during the asylum process. However, we control for geographical differences in section C in the Additional file 1: Appendix. Source: GEOSWEDEN (2018) and the Swedish Migration Agency (2018)

Models 1 and 2 show the estimated effect of residency status on total number of registered unemployment days in an individual's first 16 months in Sweden. Based on the Model 1 estimate, those with permanent residence were registered as unemployed on average for 24 days more than those with temporary residency. When we include demographic controls the coefficient changes only marginally indicating that those with permanent residence permits registered 18 more unemployment days.

The variable Study Grant is measured in 100s of SEK (roughly equivalent to \$13 USD in 2014) and as such the coefficient on Perm Res shows that permanent residents took out on average roughly 650 SEK more in their first year of residency. This form of financial assistance is only available to those that are enrolled in a study program so the fact

Table 2 Baseline results: Effects of residence status

\begin{tabular}{|c|c|c|c|c|c|c|}
\hline & \multicolumn{2}{|c|}{ Unemployed Days } & \multicolumn{2}{|c|}{ Study Grants } & \multicolumn{2}{|c|}{ Declared Income } \\
\hline & (1) & (2) & (3) & (4) & (5) & (6) \\
\hline & Basic & W. controls & Basic & W. controls & Basic & W. controls \\
\hline \multirow[t]{2}{*}{ Perm Res } & $23.52^{* * *}$ & $17.94^{* *}$ & $6.447^{* *}$ & $8.357^{* * *}$ & $-194.1^{* * *}$ & $-158.5^{* * *}$ \\
\hline & $(8.449)$ & $(8.439)$ & $(2.896)$ & $(3.002)$ & $(47.56)$ & $(44.34)$ \\
\hline N & 903 & 903 & 903 & 903 & 903 & 903 \\
\hline
\end{tabular}


that temporary residents received less study grants than permanent residents indicates that they generally spent less time in education. The September 2012 cohort of Syrians received on average 644 SEK in study grant compared to 1288 among the 2013 September cohort yielding a difference of 644 SEK, equivalent to the 6.44 point estimate in the basic model. Such a figure is low in absolute terms, but represents a doubling of expected study grants among the permanent resident group. When controls are included the magnitude of the coefficient increases to 8.4 (840 SEK).

Lastly, the estimated effect of residency status on income is such that individuals with temporary residency, our control group, declared on average 19,400 SEK more after their first year than did those with permanent residency. The inclusion of demographic controls reduces this estimate somewhat, but even so the estimate is an increase in declared income of 15,900 SEK among temporary residents.

In order to further test the robustness of our baseline results, we extend the time period of comparison, increasingly adding one month at the time to each of our groups, until December. Although this test gives larger samples, it also brings problems with sorting as a larger share of individuals applied after the policy change was instigated. However, the estimates are rather stable as the time period is extended. We also perform a placebo analysis in which we compare all other newly arrived refugees granted residence in the same time period. Estimates with this placebo group yield largely insignificant estimates. More specifically, the estimates regarding unemployment days as well as declared income are insignificant. There is, however, an effect on the usage of study grants in the placebo group although the estimates negative, opposite to our main test. Lastly, we conduct estimates with a matched sample derived from propensity score matching. These tests gives further support to our analysis regarding unemployment days and declared income, but yields insignificant positive, estimates considering the usage of study grants. ${ }^{12}$

\section{Difference-in-Differences}

While the above comparison is intuitive, it is potentially invalidated by year-on-year trends in the outcome variables. In order to control for such potential trends we utilize a difference-in-differences approach. Effectively, the method sets out to compare the trends in labour market inclusion observed cohort-to-cohort among Syrian asylum-seekers with that of an assumed comparable control group. The difference in post-policy outcomes of these two groups is compared to the difference in pre-policy outcomes thereby providing an estimated effect of treatment that is not confounded by time.

In our first specification we make use of non-Syrian asylum-seekers that arrived in the same period as our Syrian sample as the control group. ${ }^{13}$ That is, we compare the 2012 Syrian cohort to the 2012 cohort of all other asylum-seekers, and the 2013 Syrian cohort to the 2013 cohort of all other asylum-seekers. We estimate the year-on-year trend as identified by the Year term in Table 3 which takes on the values of 1 for the 2013 cohort (outcomes measured in 2014) and 0 for the 2012 cohort (outcomes measured in 2013). Further, we include a dummy variable which indicates if the observation belongs to the Syrian sample (1) or if they belong to the group of other countries (0). Lastly, we interact

\footnotetext{
$\overline{12}$ For robustness regarding extended time periods and propensity score matching, see Additional file 1: Appendix. ${ }^{13}$ We have restricted our sample of other newly arrived refugees (non-Syrian) to exclude those migrating from "uncommon" sending-countries with less than 35 individuals over the time period. This is done to avoid that smaller groups of refugees get significant weights in the synthetic control group approach (see the next subsection). The sample consist of refugees with residence permits from 19 countries/geographical areas granted residence in the same time as the Syrian cohorts.
} 
Table 3 Difference-in-differences specification - Other new arrivals

\begin{tabular}{|c|c|c|c|c|c|c|}
\hline & \multicolumn{2}{|c|}{ Unemployed Days } & \multicolumn{2}{|c|}{ Study Grants } & \multicolumn{2}{|c|}{ Declared Income } \\
\hline & $(1)$ & (2) & (3) & (4) & (5) & (6) \\
\hline & Basic & W. controls & Basic & W. controls & Basic & W. controls \\
\hline \multirow[t]{2}{*}{$\overline{Y e a r}$} & $-12.45^{*}$ & $-14.17^{* *}$ & -5.347 & -4.949 & 36.28 & 24.39 \\
\hline & $(7.12)$ & $(6.94)$ & $(3.45)$ & (3.19) & (31.03) & $(30.63)$ \\
\hline \multirow[t]{2}{*}{ Syrian } & -4.49 & -11.83 & $-17.94^{* * *}$ & $-11.99 * * *$ & $259.07^{* * *}$ & $235.25^{* * *}$ \\
\hline & (8.89) & $(8.72)$ & $(4.31)$ & $(4.01)$ & $(38.73)$ & $(38.50)$ \\
\hline \multirow[t]{2}{*}{ Year x SR } & $35.97^{* * *}$ & $32.91^{* * *}$ & $11.79^{* *}$ & $10.93^{* *}$ & $-230.37^{* * *}$ & $-204.27^{* * *}$ \\
\hline & $(11.17)$ & $(10.93)$ & $(5.42)$ & $(5.03)$ & $(48.67)$ & $(48.25)$ \\
\hline \multirow[t]{2}{*}{ Constant } & $138.37^{* * *}$ & $81.55^{* * *}$ & $24.39^{* * *}$ & $71.64^{* * *}$ & $131.55^{* * *}$ & 59.55 \\
\hline & $(5.24)$ & $(9.80)$ & $(2.54)$ & $(4.51)$ & $(22.83)$ & $(43.25)$ \\
\hline N & 2,025 & 2,025 & 2,025 & 2,025 & 2,025 & 2,025 \\
\hline$R^{2}$ & 0.01 & 0.05 & 0.01 & 0.16 & 0.02 & 0.06 \\
\hline
\end{tabular}

these two terms to obtain our difference-in-differences estimate. If the cohort trend in the outcome variable differs for the Syrian sample in comparison to the group of other arrivals, we assume that this difference is due to the change in SMA directives, and thus, is the result of permanent residency. We also include the same pre-treatment controls as above.

As can be seen in Table 3, the estimates produced from the difference-in-differences specification are substantially larger in magnitude compared to the experimental setup for all included measures. Nevertheless, they mirror the base-line results, and the differencein-difference estimates, i.e. the interaction terms, are statistically significant at the $95 \%$ confidence level in all 6 models.

There is a clear increase in the usage of unemployment days in the Syrian cohort after the introduction of permanent residency. The amount of declared income, on the other hand, decreases after the introduction of permanent residency. Lastly, the usage of study grants increases among the 2013 Syrian cohort, which were granted permanent residency.

\section{Synthetic control group}

A difference-in-differences model provides unbiased causal estimates under the assumption that the treated group would have followed the same trend as the comparison group in the absence of treatment (Angrist and Pischke 2008). However, in the event that this assumption does not hold, resulting estimates are potentially invalid. As such, in our final empirical estimation method we utilize a synthetic control, which allows one to empirically define the comparison group in a generalized difference-in-differences approach (Abadie et al. 2010).

This approach has two distinct advantages that contribute to the overall aim of the paper. First, it provides an empirically chosen comparison group that perfectly matches the trend in labour market outcomes for Syrian asylum-seekers in the pre-treatment period. As such, we have a stronger claim that the common trend assumption is valid. Second, because we must include a second pre-treatment cohort, we must adjust the measurement period for our dependent variables such that outcomes are measured in the 
same year as the migrant arrived in Sweden rather than one year later. This provides the opportunity to identify not only if there is a shift in expected outcomes as the result of the change in SMA directive, but also to determine if such differences manifest at the earliest stages of a refugee's time in Sweden.

We use three cohorts as the basis for our synthetic control estimates - those granted residency in 2012, 2013, and 2014. However, we restrict our sample to only those that arrived in August or prior in each given year because the policy directive changed in September 2013. This ensures that both the 2012 and 2013 cohorts can be viewed as fully untreated, and the 2014 cohort as fully treated. A second potential limitation to this estimation strategy is related to data availability. 2014 is the last year of data available which means that we must measure the outcomes in the same year in which one was granted asylum. As such, results should be viewed as the estimated effect of residency status in the very short-term.

The synthetic control method is appropriate when treatment is assigned at the aggregate level (Abadie et al. 2010; Abadie et al. 2015; Fowler 2013). In our case, the treatment assignment is the assignment of permanent residency, which is applied to the group of Syrian asylum-seekers from September 2013 and onward. Since the change in process affected Syrian refugees only, the pool of refugees from other countries can be seen as potential control units that can act as counterfactual cases. Given a set of pre-intervention outcomes, in our case the average unemployment measured in 2012 and 2013, the synthetic control method seeks to find a set of weights, w, that can be applied to the donor pool of potential control cases such that the outcome measures in the pre-treatment period between the synthetic control and observed treatment group are equal. In other words, the method finds an weighted combination of control units such that the common trend assumption is satisfied in the pre-treatment period (we still must make the assumption that it is satisfied in the post-treatment period, which is inherently untestable). In effect, the method finds a control group such that:

$$
\bar{Y}_{t}^{k}=\sum_{c=1}^{j} * w_{c} * \bar{Y}_{c}^{k}
$$

where $\mathrm{Y}$ is the variable of interest, subscripts $\mathrm{t}$ and $\mathrm{c}$ denote the treatment and control cases, $j$ is the number of control units, and superscript $k$ indexes the pre-treatment measurements of $\mathrm{Y}$.

The donor pool of potential control cases consists of 19 non-EU units (SMA designated geographical regions - primarily countries but in some instances groups of smaller countries from a distinct geographic area) - from which a minimum 35 individuals were awarded residence permits on humanitarian grounds. ${ }^{14}$ The synthetic control units differ for each of our three outcome variables, but in all but one analysis (unemployment days), every possible donor unit is given positive weight. However, in all three cases the empirical control is largely dominated by two units, with the remaining units receiving marginal weights. See the Additional file 1: Appendix for weightings.

Given that the algorithm was successful in finding a pre-treatment match for Syrian refugees, we can examine the difference in the trends post-treatment in order to draw inference of the effect of the reform. Figure 3a shows that the level of unemployment days

\footnotetext{
${ }^{14}$ These are the same 19 geographical regions that make up the comparison group in the standard difference-in-differences estimates discussed earlier.
} 

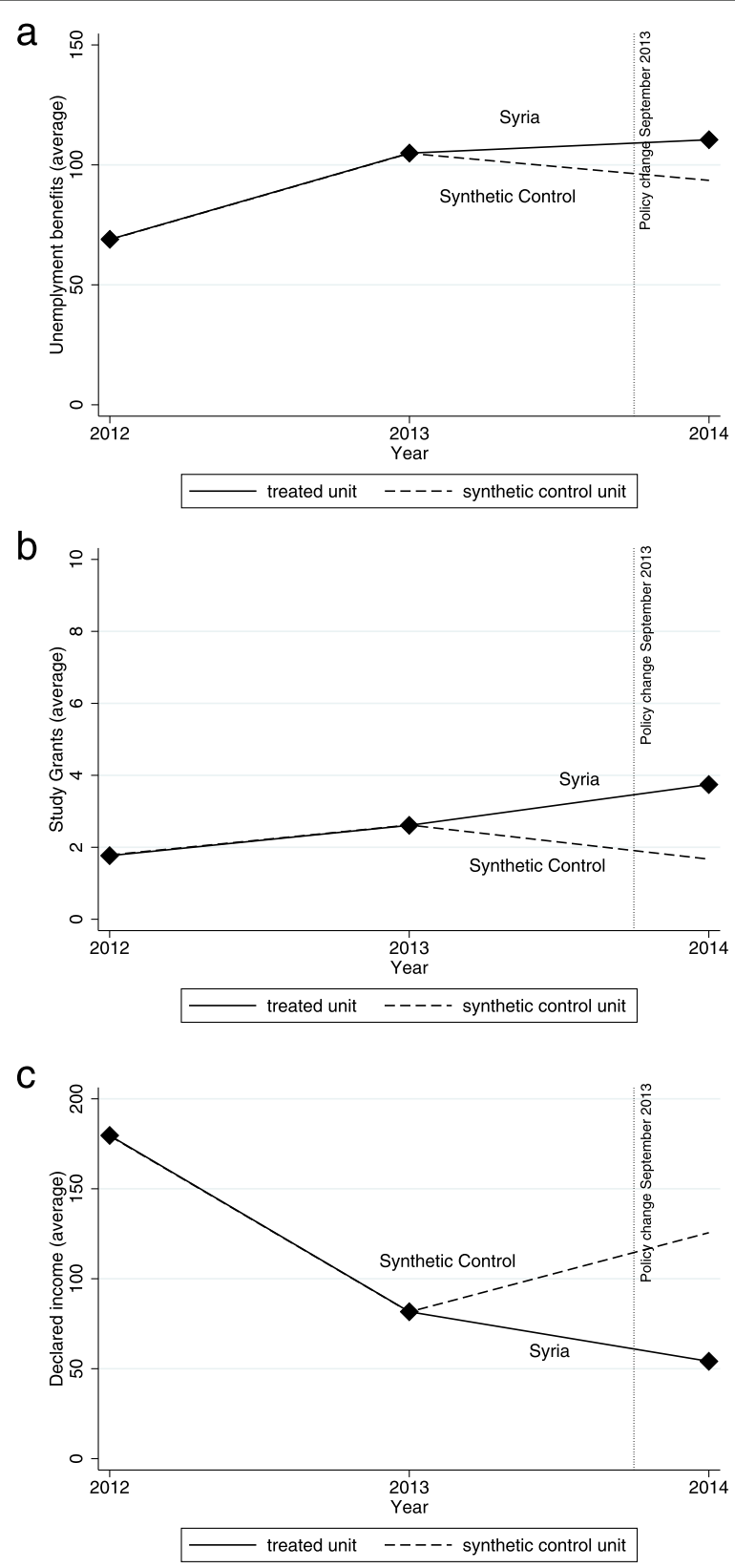

Fig. 3 Trends in unemployment days, study grants, and declared income. Notes: The figures report the level of unemployment days (a), study grants $(\mathbf{b})$, and declared income (c) among Syrians and the synthetic control unit across three points in time. The synthetic control unit consist of a weighted average of all other individuals granted residence permits on humanitarian grounds in Sweden

is higher for Syrians granted permanent residency than for the synthetic control unit. Effectively, Syrian refugees in 2014 were registered as unemployed for 16 more days on average in 2014 than the weighted average of those individuals that make up the control unit. The results for declared income are similarly consistent with our main estimates; Syrians were expected to have declared 7100 SEK less in 2014 than the synthetic control group. The short time-frame of these estimates must be kept in mind - these estimates are measured at the end of 2014 for individuals that were granted residency in 2014. Given 
such a short time period, and given that the average income for the 2014 cohort of Syrian refugees in 2014 was approximately 54,100 SEK, 7,100 SEK is a non-trivial estimate. The final outcome variable in our study is the use of study grants, defined as the amount of study grants in SEK that refugees received in a given year. Here we find that Syrian refugees received on average more study grants than did their counterparts in the synthetic control group. On average, a Syrian is expected to have secured 200 SEK more at the end of their first year in Sweden than was observed in the synthetic control group.

Taken together, the estimates above provide a rather coherent picture, and one which is highly consistent with our main investigation. In addition, we perform randomization inference on the 19 countries that make up the synthetic control pool. For each dependent variable we perform the same analysis, while excluding Syrians. Regarding unemployment days, only three other groups provide a larger increase than the Syrian sample; in the randomization inference regarding declared income four other groups provide larger negative estimates; lastly, regarding study grants, six other populations show similar increases. Therefore, although not without uncertainty, the consistency of the synthetic control results with our other estimation techniques increases our overall confidence in the effect of permanent residency. See the Additional file 1: Appendix for the randomization inference results.

\section{Discussion and concluding remarks}

A number of scholars have pointed to a general trend of convergence towards increasingly restrictive migration policies and a multicultural backlash across European nation-states (Joppke 2007; Vertovec and Wessendorf 2010). Similarly, political parties and scholars have emphasized that individuals that need to make an effort to remain in the country of destination in order to have a better chance to integrate into the main society. A few studies have evaluated the effect of civic integration measures. However, few of these studies explicitly focus on residency status and its effect on labour market inclusion.

In this study, we have attempted to fill this knowledge gap by exploiting a policy change concerning the residency status of Syrian asylum-seekers in Sweden. We examine the policy change with respect to labour market inclusion defined as unemployment days, study grants received, and declared income. A few problematic aspects of the policy change in combination with the difficulty of estimating labour market outcomes led us to perform several analyses; a difference-in-means approach as well as a difference-in-differences design and a synthetic control group approach. Our estimation techniques produce very similar patterns, which gives greater confidence in our overall results than would be derived from a single method. Further, the methods provide us with estimates at different time points - outcomes in the cohort study are measure 16 months after residency and outcomes in the synthetic control models are measured 4 to 8 months after granted residency. This helps us to understand not only if, but also when, differences become apparent in the short-term.

We argue that the shift in directives by the SMA represented a fundamental change in the security of residence for newly arrived Syrians. We argue that a shift to more secure residency represents a shift towards a more rights-based approach to migration. Consequently, this shift that the SMA implemented represents movement away from a responsibilities-based approach to migration, which is typically grounded in theories of civic integration. Migration policy in its entirety is defined by many more features than 
this single dimension, and we are careful to avoid any claim to the study of different migration policy regimes. Rather than a weakness, this continuity in migration policy is a strength of this study as it allows us to identify an individual dimension such that all other relevant institutional and cultural factors of the recipient country remain constant. Such an opportunity allows us to estimate the effect of differing levels of security of residency within a single institutional context, rather than deriving inference from the comparison of many contexts, in which all factors that define migration policy are bundled.

In general we find that temporary residents perform significantly better than permanent residents with respect to unemployment and declared income. Across both our cohort studies and the synthetic control we find that Syrian asylum-seekers that were granted temporary residence registered for fewer unemployment days, and that they have higher declared incomes. With respect to study grants received, our operationalization of time spent in education, we find rather that permanent residents outperformed temporary residents.

Advocates of responsibilities-based migration policy frequently argue that such approaches provide an incentive, or "push", for individuals to integrate into society and the labour market. From this perspective our results can be seen as supportive of this claim, at least in the short-term - temporary residents that are subject to a relatively less-inclusive situation earn more and are unemployed less. However, at the same time, they are less likely to spend time in education than are those with permanent residency. Given that those that study in their new country after they receive residency have higher incomes and fewer unemployment days in the long-term, this is a potential worry for the success of temporary relative to permanent residents in the long-term.

Given that permanent residency is beneficial for short-term education, but temporary residency is beneficial for short-term income and unemployment, our results cannot be said to offer a clear adjudication of which approach is empirically advantageous. Rather, it would appear that both the rights-based and responsibilities-based approaches have their own distinct benefits. While the political debate about the issue is often framed in such empirical terms - that one approach will lead to greater or worse outcomes for the target group according to a common outcome - our results suggest that both approaches can be supported empirically, albeit with different metrics for success. In our view then, the issue should be framed in normative terms. Rather than debate whether one approach will lead to greater inclusion than the other, focus should be shifted to discussing the type of inclusion that the different approaches are likely to provide - short-term employment versus potential long-term benefits.

Our findings advocate for further research into how other outcomes are affected by the shift from temporary to permanent residency - or similar shifts in the rights - and responsibilities-based migration framework. While we study labour market inclusion in the short-term, migration policy is wide-ranging and its potential outcomes innumerable. As our conclusions are drawn in relation to labour market inclusion, it is entirely plausible, and indeed likely, that other outcomes such as inclusion along other dimensions such as social, political, or health and well-being, could be more clearly differentiated along empirical lines. Future research on the impact of residence status have high relevance from an international as well as from a Swedish perspective given the general restrictive trend in migration policy (Joppke 2007). In Sweden, the implementation of a migration law in 2016, introducing temporary residence as the norm, have dramatically 
highlighted the need for further research in this area. With the conclusions of this paper in mind, it is possible that the now prevailing Swedish regulations promote similar patterns of inclusion in the short-term, potentially with important implications on future societal development and patterns of inclusion. Existing qualitative evidence from Sweden suggest that the 2016 change had similar effects as reported here: residents with temporary permits perceive that they have less opportunity to pursue an education because of their limited residence (Beskow 2018, p. 57). The consequences of residence status on inclusion is thus an important question for future studies to address.

\section{Supplementary Information}

The online version contains supplementary material available at https://doi.org/10.1186/s40878-020-00203-3.

Additional file 1: Appendix.

\section{Acknowledgments}

The authors are grateful to two anonymous reviewers, Emma Holmqvist, Susanne Urban, Henrik Andersson, Per Adman, Gunnar Myrberg and seminar participants at the Institute for Housing and Urban Research and Uppsala Center for Labour Studies for helpful comments and suggestions on earlier versions of this text.

\section{Authors' contributions}

The authors have contributed equally to the design and implementation of the research. These parts include the drafting and design of the work, the data collection, the analysis and interpretation, and the drafting and critical revision of the article. The authors read and approved the final manuscript.

\section{Funding}

Open access funding provided by Uppsala University.

\section{Availability of data and materials}

In this study, we make use of individual-level microdata provided by Statistics Sweden (the data comes from the GeoSweden database, managed by the Institute of Housing and Urban Research at Uppsala University). This is restricted access data; we are not allowed by Statistics Sweden to share the data with any third part. For this reason, we need to request for an exemption from the policy to provide the raw data used.

\section{Competing interests}

The authors declare that they have no competing interests.

Received: 30 January 2020 Accepted: 2 September 2020

Published online: 09 November 2020

\section{References}

Abadie, A., Diamond, A., Hainmueller, J. (2010). Synthetic control methods for comparative case studies: Estimating the effect of california's tobacco control program. Journal of the American statistical Association, 105(490), 493-505.

Abadie, A., Diamond, A., Hainmueller, J. (2015). Comparative politics and the synthetic control method. American Journal of Political Science, 59(2), 495-510.

Aldén, L., \& Hammarstedt, M. (2014). Utrikes Födda På Den Svenska Arbetsmarknaden: en Översikt Och en Internationell jämförelse [Foreign-born individuals on the Swedish labor market: An overview and an international comparison]. Växjö: Linnaeus Univeristy.

Andersson, H., \& Jutvik, K. (2019). Do asylum-seekers respond to policy changes? Evidence from the Swedish-Syrian case (Working Paper). APSA Preprints. https://doi.org/10.33774/apsa-2019-6f46m.

Angrist, J., \& Pischke, J. (2008). Mostly harmless econometrics. Princeton: Princeton University Press.

Bakker, L., Dagevos, J., Engbersen, G. (2014). The importance of resources and security in the socio-economic integration of refugees. a study on the impact of length of stay in asylum accommodation and residence status on socio-economic integration for the four largest refugee groups in the Netherlands. Journal of International Migration and Integration, 15(3), 431-448.

Bee, C., \& Pachi, D. (2014). Active citizenship in the UK: Assessing institutional political strategies and mechanisms of civic engagement. Journal of Civil Society, 10(1), 100-117.

Beskow, L. (2018). Humanitära konsekvenser av den tillfälliga utlänningslagen [Humanitarian consequences of the temporary migration law]. Stockholm: Red Cross.

Bevelander, P., Hagström, M., Emilsson, H. (2009). Asylsökandes eget boende, EBO - en kartläggning [Asylumseekers own housing, EBO - an overview], In SOU; 2009:19: 609. Stockholm: Fritzes.

Bevelander, P., \& Pendakur, R. (2014). The labour market integration of refugee and family reunion immigrants: A comparison of outcomes in Canada and Sweden. Journal of Ethnic and Migration Studies, 40(5), 689-709.

Blomqvist, N., Skogman Thoursie, P., Tyrefors, B. (2018). Restricting residence permits: Short-run evidence from a Swedish reform (Working Paper). https://doi.org/10.1561/100.00012055. 
Bogic, M., Njoku, A., Priebe, S. (2015). Long-term mental health of war-refugees: a systematic literature review. BMC International Health and Human Rights, 15(1), 29.

Borevi, K. (2002). Välfärdsstaten i det mångkulturella samhället [The Welfare State in a Multicultural Society]. PhD thesis, Acta Universitatis Upsaliensis.

Borevi, K. (2010). Dimensions of citizenship: European integration policies from a Scandinavian perspective. In B. Bengtsson, P. Strömblad, A.-H. Bay (Eds.), Diversity, inclusion and citizenship in Scandinavia. Newcastle upon Tyne: Cambridge Scholars Publishing.

Borevi, K., Jensen, K.K., Mouritsen, P. (2017). The civic turn of immigrant integration policies in the Scandinavian welfare states. Comparative Migration Studies, 5(1), 1-14.

Chiswick, B.R. (1978). The effect of Americanization on the earnings of foreign-born men. Journal of Political Economy, 86(5), 897-921.

Chiswick, B.R. (1991). Speaking, reading, and earnings among low-skilled immigrants. Journal of Labor Economics, 9(2), 149-170.

Dahlstedt, I., \& Bevelander, P. (2010). General versus vocational education and employment integration of immigrants in Sweden. Journal of Immigrant \& Refugee Studies, 8(2), 158-192.

Esping-Andersen, G. (1990). The Three Worlds of Welfare Capitalism. New Jersey: Princeton University Press.

Ferrer, A., Green, D.A., Riddell, W.C. (2006). The effect of literacy on immigrant earnings. Journal of Human Resources, 41(2), $380-410$

Fowler, A. (2013). Electoral and policy consequences of voter turnout: Evidence from compulsory voting in Australia. Quarterly Journal of Political Science, 8(2), 159-182. https://doi.org/10.1561/100.00012055.

GEOSWEDEN (2018). Database managed by the Institute for Housing and Urban Research.

Goodman, S.W. (2010). Integration requirements for integration's sake? identifying, categorising and comparing civic integration policies. Journal of Ethnic and Migration Studies, 36(5), 753-772.

Goodman, S.W. (2011). Controlling immigration through language and country knowledge requirements. West European Politics, 34(2), 235-255.

Goodman, S.W., \& Wright, M. (2015). Does mandatory integration matter? effects of civic requirements on immigrant socio-economic and political outcomes. Journal of Ethnic and Migration Studies, 41(12), 1885-1908.

Hammarstedt, M. (2003). Income from work among immigrants in Sweden. Review of Income and Wealth, 49(2), 185-203.

Joppke, C. (2004). The retreat of multiculturalism in the liberal state: theory and policy. The British Journal of Sociology, $55(2), 237-257$.

Joppke, C. (2007). Beyond national models: Civic integration policies for immigrants in western Europe. West European Politics, 30(1), 1-22

Joppke, C. (2017). Civic integration in Western Europe: three debates. West European Politics, 40(6), 1153-1176.

Jörum, E. (2015). Valet och vägen - en intervjustudie med nyanlända syrier i Sverige [The choice and the road - an interview study with newly arrived Syrians in Sweden]. DELMI, 8, 36-37.

Kelly, M., \& Hedman, L. (2016). Between opportunity and constraint: Understanding the onward migration of highly educated iranian refugees from Sweden. Journal of International Migration and Integration, 17(3), 649-667.

Kesler, C. (2006). Social policy and immigrant joblessness in Britain, Germany and Sweden. Social Forces, 85(2), 743-770.

Kogan, I. (2006). Labor markets and economic incorporation among recent immigrants in Europe. Social Forces, 85(2), $697-721$.

Kogan, I. (2007). Working Through Barriers. Dordrecht: Springer.

Koopmans, R. (2005). Contested Citizenship: Immigration and Cultural Diversity in Europe, vol. 25. Minneapolis: University of Minnesota Press.

Koopmans, R. (2010). Trade-offs between equality and difference: Immigrant integration, multiculturalism and the welfare state in cross-national perspective. Journal of Ethnic and Migration Studies, 36(1), 1-26.

Larsen, B., Kilström, M., Olme, E. (2018). Should I stay or must I go: Temporary protection and refugee outcomes (Working Paper, No. 5-2018). Copenhagen Business School.

Larsson, J.K. (2015). Integrationen Och Arbetets Marknad: Hur Jämställdhet, Arbete Och Annat" Svenskt" Görs Av Arbetsförmedlare Och privata aktörer [The Market of Integration and Labour: How gender equality, labour and other "Swedish" phenomena are constructed by employment service officials and private actors]. Stockholm: Atlas Akademi.

Lemaître, G., \& Liebig, T. (2007). Jobs for Immigrants: Labour Market Integration in Australia, Denmark, Germany and Sweden, vol. 1. Paris: Publications de l'OCDE.

Mansouri, F., Leach, M., Nethery, A. (2010). Temporary protection and the refugee convention in Australia, Denmark, and Germany. Refuge: Canada's Periodical on Refugees, 26(1), 135-147.

Mincer, J. (1974). Schooling, experience, and earnings. Human behavior and social institutions no. 2. Cambridge: National Bureau of Economic Research.

Nekby, L. (2002). How long does it take to integrate? Employment convergence of immigrants and natives in Sweden (Working paper). FIEF Stockholm.

OECD (2020). Foreign-born unemployment (indicator). OECD. https://data.oecd.org/migration/foreign-bornunemployment.htm. Accessed 30 June 2020.

OECD (2016a). The labour market integration of immigrants and their children in Sweden. Paris: OECD Publishing

OECD (2016b). Making integration work: Refugees and others in need of protection. Paris: OECD Publishing.

RCI 14/2012 (2012). Rättsligt ställningstagande angäende säkerhetssituationen i Syrien [Legal standpoint regarding the situation in Syria]. Swedish Migration Agency.

RCI 14/2013 (2013). Rättsligt ställningstagande angående säkerhetssituationen i Syrien [Legal standpoint regarding the situation in Syria]. Swedish Migration Agency.

Ryan, D., Dooley, B., Benson, C. (2008). Theoretical perspectives on post-migration adaptation and psychological well-being among refugees: Towards a resource-based model. Journal of Refugee Studies, 21(1), 1-18.

Strik, T., Böcker, A., Luiten, M., van Oers, R. (2010). The INTEC project: synthesis report. Integration and naturalisation tests: the new way to European citizenship. Nijmegen: Centre for Migration Law, Radboud University Nijmegen.

Swedish Migration Agency (2018). Statistics. https://www.migrationsverket.se/Om-Migrationsverket/Statistik.html. Accessed 30 June 2020 
Vertovec, S., \& Wessendorf, S. (2010). The Multiculturalism Backlash: European Discourses, Policies and Practices. London and New York: Routledge.

World Bank (2020). GDP Growth (indicator). World Bank. https://data.worldbank.org/. Accessed 30 June 2020.

\section{Publisher's Note}

Springer Nature remains neutral with regard to jurisdictional claims in published maps and institutional affiliations.

Submit your manuscript to a SpringerOpen ${ }^{\circ}$ journal and benefit from:

- Convenient online submission

- Rigorous peer review

- Open access: articles freely available online

- High visibility within the field

- Retaining the copyright to your article

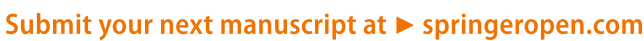

